\title{
Titers of Anti-Brucella Antibodies by Enzyme Linked Immunosorbant Assay in Vaccinated and Unvaccinated Brucellosis Infected Cattle
}

\author{
Sugandha Raj ${ }^{1}$, Hari Mohan Saxena ${ }^{*}$, Sikh Tejinder Singh ${ }^{2}$ \\ ${ }^{1}$ Department of Veterinary Microbiology, Guru Angad Dev Veterinary and Animal Sciences University, Ludhiana, India \\ ${ }^{2}$ Department of Animal Genetics and Breeding, Guru Angad Dev Veterinary and Animal Sciences University, Ludhiana, India \\ Email: *drhmsaxena@gmail.com
}

How to cite this paper: Raj, S., Saxena, H.M. and Singh, S.T. (2017) Titers of Anti-Brucella Antibodies by Enzyme Linked Immunosorbant Assay in Vaccinated and Unvaccinated Brucellosis Infected Cattle. Open Journal of Veterinary Medicine, 7, 131-137. https://doi.org/10.4236/ojvm.2017.710013

Received: August 11, 2017

Accepted: October 22, 2017

Published: October 25, 2017

Copyright (c) 2017 by authors and Scientific Research Publishing Inc. This work is licensed under the Creative Commons Attribution International License (CC BY 4.0).

http://creativecommons.org/licenses/by/4.0/

cc) (i) Open Access

\begin{abstract}
Brucellosis is an important re-emerging zoonotic disease caused by Brucella organisms. In the absence of a Differentiation of Infected from Vaccinated Animal (DIVA) assay for bovine Brucellosis, it becomes difficult to assess whether the anti-Brucella antibody response in an animal is due to vaccination or infection. We compared the anti-Brucella antibody titers of naturally Brucellosis affected unvaccinated cows, previously vaccinated infected cows, normal healthy vaccinated cows and healthy unvaccinated calves. The titers of anti-Brucella antibodies were estimated by indirect ELISA. The mean titer $\left(\log _{10}\right)$ was found to be $1.518 \pm 0.005$ in case of naturally Brucellosis affected cattle which had been vaccinated during calf hood. The mean titer in case of naturally infected cattle which had never been vaccinated was $1.5441 \pm 0.005$. The mean titer in healthy unaffected cattle vaccinated during calf hood was $1.504 \pm 0.002$ and that of unvaccinated healthy calves was $0.560 \pm 0.016$. It was interesting to find that the antibody titers in naturally affected cattle which had never been vaccinated were very significantly $(p<0.01)$ higher than those of Brucellosis affected cows which had been vaccinated during calf hood. The titer in vaccinated infected cattle was very significantly $(p<0.01)$ higher than that of uninfected vaccinated cows.
\end{abstract}

\section{Keywords}

Antibody Titer, Brucella, Brucellosis, Bovine, ELISA

\section{Introduction}

Brucellosis is endemic in India and is prevalent in all parts of the country. It 
causes heavy economic losses to the industry through delayed conception, late-term abortions, and retention of placenta [1] in females and orchitis and epididymitis in males. The organisms are excreted in semen, uterine discharges, and milk [2]. The occurrence of the disease varies from $10 \%$ in marginal herds to $50 \%$ in organized farms.

The Brucella abortus strain 19 vaccine against bovine Brucellosis has been found to be very useful under most conditions but has some undesirable traits also [3]. Although vaccination with S19 is effective in preventing Brucellosis in cattle and buffaloes, it is not uncommon to find adult cattle vaccinated in calf hood with S19 vaccine, getting naturally infected with Brucellosis [4]. Although there is vast information on various aspects of bovine Brucellosis in the available literature, there is hardly any systematic study on the comparison of antibody levels between infected and vaccinated animals. We therefore compared the antibody titers of different categories of animals by ELISA to investigate if titers alone could indicate whether the animal is infected or vaccinated. ELISA has been claimed to be more sensitive followed by RBPT and STAT when applied to cattle sera. The present study offers valuable insight which could help in devising appropriate control strategies for this dreaded zoonosis.

\section{Materials and Methods}

Permission of the Institutional Animal Ethics Committee (IAEC) was obtained and IAEC guidelines were followed throughout the study.

\subsection{Collection of Serum}

Blood samples were collected from naturally infected clinical cases of Brucellosis in cattle which had never been vaccinated (6) identified in villages in and around Ludhiana district, from naturally infected animals vaccinated during calfhood (21), normal healthy (uninfected) vaccinated cattle (6) and healthy unvaccinated calves (6) of a dairy farm in Haibowal area, Ludhiana. Sera were separated from clotted blood and stored at $-20^{\circ} \mathrm{C}$ till further use for studying the antibody response of the animals.

\subsection{Rose Bengal Plate Test (RBPT)}

RBPT was carried out on sera as per the standard method [5]. Equal volumes (25 $\mu \mathrm{l}$ each) of RBPT colored antigen (Punjab Veterinary Vaccine Institute, Ludhiana) and test serum were mixed on a clean glass slide. The slide was observed till $3 \mathrm{~min}$. for formation of clumps. Formation of clumps (agglutinate) indicated a positive reaction while the absence of clear clumps was considered as a negative reaction.

\subsection{Enzyme Linked Immunosorbant Assay (ELISA)}

Serum samples of cattle were tested by ELISA [6] using Ingezim Brucella Bovina 2.0 Brucellosis serum ELISA test kit (Ingenasa). ELISA was carried out as per the 
manufacturer's instructions accompanying the kit described below.

a) $90 \mu \mathrm{l}$ of diluent was added in each well of the plate except the ones destined as controls. $10 \mu \mathrm{l}$ of diluted individual sample (1/10) was added to the remainder wells of the plate.

b) $100 \mu \mathrm{l}$ of the controls provided in the kit were added. Plate was incubated for 1 hour at room temperature (RT, $\left.20^{\circ} \mathrm{C}-25^{\circ} \mathrm{C}\right)$.

c) The plate was washed three times with $300 \mu$ l of washing solution.

d) $100 \mu \mathrm{l}$ of the conjugate was added to each well and plate was incubated for 30 minutes at room temperature. The plate was washed three times with $300 \mu \mathrm{l}$ washing solution.

e) $100 \mu$ of substrate was added to each well and plate was kept in dark for 10 min at RT.

f) $100 \mu \mathrm{l}$ of the stop solution was added to each well.

g) Optical density (O.D.) of each well with spectrophotometer was done at 450 $\mathrm{nm}$ within 5 minutes after the addition of stop solution.

The test was valid when: O.D. value for positive control serum was $\geq 1.0$, and was considered negative when the OD of the control serum was $\leq 0.2$.

Cut off $=\mathrm{OD}_{450 \mathrm{~nm}}$ positive Control $\times 0.4=40 \%$ positivity

\subsection{Statistical Analysis of Data}

Data pertaining to serum antibody titers was statistically analyzed by ANOVA.

\section{Results and Discussion}

The antibody titers estimated by ELISA are presented in Tables 1-4; Figure 1. The mean antibody titer $\left(\log _{10}\right)$ in case of Brucellosis affected cattle which had been vaccinated during calf hood was found to be $1.518 \pm 0.005$ (Table 1). The mean titer in case of naturally infected cattle which had never been vaccinated was $1.5441 \pm 0.005$ (Table 2). In case of healthy unaffected cattle vaccinated during calf hood the mean titer was $1.504 \pm 0.002$ (Table 3 ) and in unvaccinated healthy calves it was $0.560 \pm 0.016$ (Table 4). It was interesting to find that in naturally affected cattle which had never been vaccinated previously the antibody titers were very significantly $(p<0.01)$ higher than those of Brucellosis affected cattle which had been vaccinated during calf hood and normal healthy vaccinated cattle unaffected by the disease. The mean titer in Brucellosis affected cattle which had been vaccinated during calf hood was very significantly ( $p<$ 0.01 ) higher than that of normal healthy vaccinated cattle unaffected by the disease.

The differences between mean titers of vaccinated infected and unvaccinated infected, vaccinated infected versus vaccinated healthy, vaccinated infected versus unvaccinated healthy, unvaccinated infected versus vaccinated healthy, unvaccinated infected versus unvaccinated healthy and vaccinated healthy versus unvaccinated healthy were very significant $(p<0.01)$.

The titers in unvaccinated infected cattle were very significantly $(p<0.01)$ 
Table 1. Titers of anti-Brucella antibody by ELISA in infected cattle vaccinated in calfhood.

\begin{tabular}{|c|c|}
\hline Animal number & Titer \\
\hline B1 & 1.5221 \\
\hline B2 & 1.5167 \\
\hline B3 & 1.5133 \\
\hline B4 & 1.5126 \\
\hline B5 & 1.5199 \\
\hline B6 & 1.5169 \\
\hline B7 & 1.5133 \\
\hline B8 & 1.5134 \\
\hline B9 & 1.5267 \\
\hline $\mathrm{B} 10$ & 1.5187 \\
\hline B11 & 1.5154 \\
\hline B12 & 1.5253 \\
\hline B13 & 1.5169 \\
\hline B14 & 1.5157 \\
\hline B15 & 1.5139 \\
\hline B16 & 1.5139 \\
\hline B17 & 1.5135 \\
\hline B18 & 1.5335 \\
\hline B19 & 1.5148 \\
\hline B20 & 1.5226 \\
\hline B21 & 1.5209 \\
\hline Mean \pm SD & $1.518 \pm 0.005$ \\
\hline
\end{tabular}

Table 2. Anti-Brucella antibody titers by ELISA in unvaccinated infected cattle.

\begin{tabular}{cc}
\hline Animal no. & Titer \\
\hline I & 1.5467 \\
II & 1.5387 \\
III & 1.5481 \\
IV & 1.5469 \\
V & 1.5361 \\
VI & 1.5481 \\
Mean \pm SD & $1.5441 \pm 0.005$
\end{tabular}


Table 3. Anti-Brucella antibody titers by ELISA in healthy vaccinated cattle.

\begin{tabular}{cc}
\hline Animal no. & Titer \\
\hline 1303 & 1.5027 \\
1431 & 1.5076 \\
1468 & 1.5045 \\
1378 & 1.5032 \\
1470 & 1.5034 \\
1374 & 1.5075 \\
Mean \pm SD & $1.504 \pm 0.002$ \\
\hline
\end{tabular}

Table 4. Anti-Brucella antibody titers by ELISA in unvaccinated healthy calves.

\begin{tabular}{cc}
\hline Animal no. & Titer \\
\hline 1632 & 0.5671 \\
1634 & 0.5589 \\
1638 & 0.5847 \\
1577 & 0.5334 \\
1575 & 0.5564 \\
1581 & 0.5634 \\
Mean \pm SD & $0.560 \pm 0.016$ \\
\hline
\end{tabular}

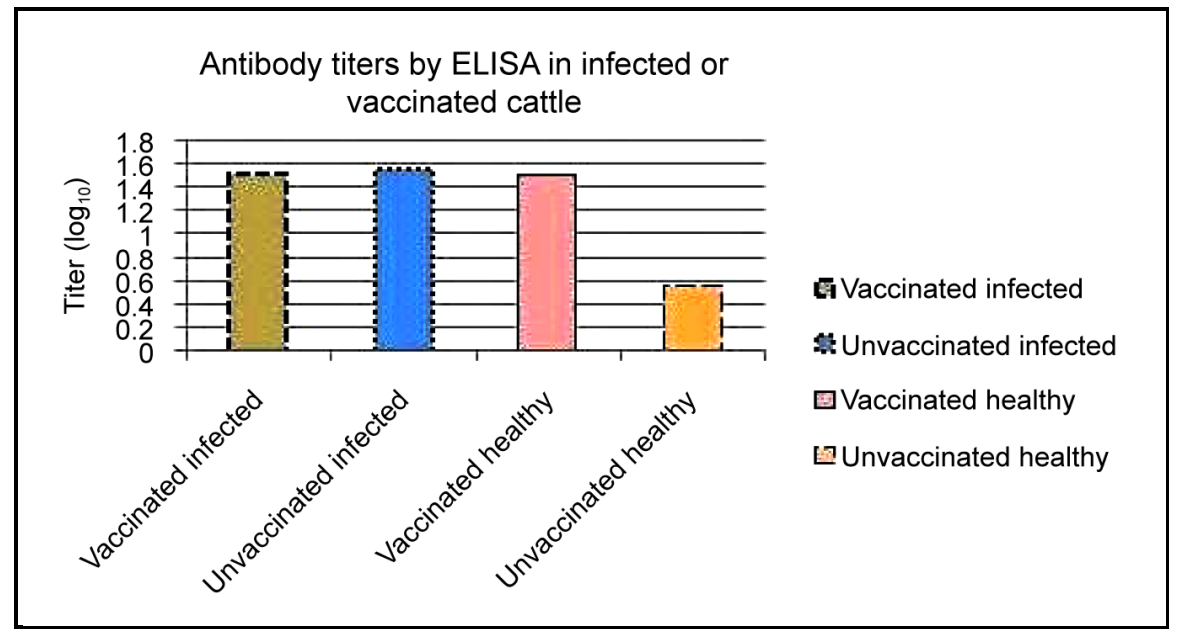

Figure 1. Antibody titers in infected and vaccinated cattle by ELISA.

higher than those of infected vaccinated, healthy vaccinated and healthy unvaccinated animals. The titers in vaccinated infected cattle were very significantly $(p$ $<0.01)$ higher than those of healthy vaccinated and healthy unvaccinated animals.

In a study [7] the performance of an ELISA for detection of total antibodies to Brucella spp. was compared with that of the Rose Bengal Plate Test, standard tube agglutination test and Coombs test in the diagnosis of Brucellosis. ELISA 
was the most sensitive test (97\%), showing greater specificity (96\%) and good predictive positive and negative values (98\% and $94 \%$ respectively). ELISA was the only positive test in $6 \%$ of patients in whom Brucellosis had been confirmed by culture. ELISA has been claimed to be more sensitive followed by RBPT and STAT when applied to cattle sera [8].

Assessment of immunological data from Brucella infected cattle can be helpful in charting the disease process, diagnosis and prognosis and may help in understanding the pathophysiology of disease. It was reported [4] that naturally affected animals have very high titers of agglutinating antibodies than the vaccinated animals.

Numerous outer and inner membrane, cytoplasmic, and periplasmic protein antigens of Brucella have been characterized, yet the antigen that dominates the antibody response is Lipopolysaccharide (LPS). Some antigens are recognized by the immune system during infection and are potentially useful in diagnostic tests.

The role of humoral immunity against intracellular bacterial infections is limited and may not be protective. Antibody mediated opsonization by immunoglobulins (IgM, IgG1, IgG2a and IgG3) enhances phagocytic uptake of bacteria, limiting the level of initial infection with Brucella but has little effect on intracellular course of infection [9] [10]. The L7/L12 ribosomal proteins are important in stimulating cell-mediated responses [11].

Since the infected animals in the first group were the ones who had already been vaccinated during calf hood, the infection in these animals may suggest that the vaccine was unable to induce adequate protective levels of antibody. Secondly, the heightened antibody response after infection in vaccinated animals may indicate a secondary immune response to Brucella antigens against which the lymphocytes were primed by calf hood vaccination.

\section{Conclusion}

The anti-Brucella antibody titers by ELISA in naturally affected unvaccinated cattle were very significantly higher than those of Brucellosis affected vaccinated cattle and normal healthy vaccinated cattle unaffected by the disease.

\section{Conflict of Interest}

The authors declare that there is no conflict of interest.

\section{Acknowledgement}

The study was funded by a grant under RKVY scheme (PI: Prof. H M Saxena).

\section{References}

[1] Kollannur, J.D., Rathore, R. and Chauhan, R.S. (2007) Epidemiology and Economics of Brucellosis in Animals and Its Zoonotic Significance. Proceedings of XIII International Congress in Animal Hygiene, Tartu, Estonia, 17-21 June 2007, 466-468. 
[2] Godfroid, J., Garin-Bastuji, B., Saegerman, C. and Blasco, J.M. (2013) Brucellosis in Terrestrial Wildlife. Revue Scientifique et Technique de I' Office International des Epizooties, 32, 27-42. https://doi.org/10.20506/rst.32.1.2180

[3] Moriyon, I., Grillo, M.J., Monreal, D., Gonzalez, D., Marin, C., Lopez-Goni, I., Mainar-Jaime, R.C., Moreno, E. and Blasco, J.M. (2004) Rough Vaccines in Animal Brucellosis: Structural and Genetic Basis and Present Status. Veterinary Research, 35, 1-38. https://doi.org/10.1051/vetres:2003037

[4] Mohan, A., Saxena, H.M. and Malhotra, P. (2016) A Comparison of Titers of Anti-Brucella Antibodies of Naturally Infected and Healthy Vaccinated Cattle by Standard Tube Agglutination Test, Microtiter Plate Agglutination Test, Indirect Hemagglutination Assay, and Indirect Enzyme-Linked Immunosorbent Assay. Veterinary World, 9, 717-722. https://doi.org/10.14202/vetworld.2016.717-722

[5] Morgan, W.J., Mackinnon, D.T., Gill, K.P.W., Gower, S.G.M. and Norris, P.I.W. (1978) Brucellosis Diagnosis: Standard Laboratory Techniques Report Series No. 1. MAFF, Weybridge, England.

[6] Falconi, C., Oleaga, A., Lopez-Olvera, J.R., Casais, R., Prieto, M. et al. (2009) Prevalence of Antibodies against Selected Agents Shared between Cantabrian Chamois and Domestic Goats. European Journal of Wildlife Research, 56, 319-325. https://doi.org/10.1007/s10344-009-0322-Z

[7] Saz, J.V., Beltrán, M., Díaz, A., Agulla, A., Merino, F.J., Villasante, P.A. and Velasco, A.C. (1987) Enzyme-Linked Immunosorbent Assay for Diagnosis of Brucellosis. Clinical Microbiology, 6, 71-74. https://doi.org/10.1007/BF02097200

[8] Ganesan, P.I. and Anuradha, P. (2006) Rose Bengal Test and Dot-ELISA in Diagnosis of Bovine Brucellosis. Indian Veterinary Journal, 83, 907.

[9] Bellaire, B.H., Roop, R.M. and Cardelli, J.A. (2005) Opsonized Virulent Brucella abortus Replicates within Non Acidic, Endoplasmic Reticulum-Negative, LAMP-1 Positive Phagosomes in Human Monocytes. Infection and Immunity, 73, 3702-3713. https://doi.org/10.1128/IAI.73.6.3702-3713.2005

[10] Baldwin, C.L. and Goenka, R. (2006) Host Immune Responses to the Intracellular Bacterium Brucella: Does the Bacterium Instruct the Host to Facilitate Chronic Infection? Critical Reviews in Immunology, 26, 407-442. https://doi.org/10.1615/CritRevImmunol.v26.i5.30

[11] Oliveira, S.C. and Splitter, G.A. (1994) Subcloning and Expression of Brucella abortus L7/L12 Ribosomal Gene and T-Lymphocyte Recognition of the Recombinant Protein. Infection and Immunity, 62, 5201-5204. 